\title{
The impact of chronic venous leg ulcers: a systematic review.
}

Dr. Julie Green

Lecturer, School of Nursing and Midwifery, Keele University, Staffordshire, ST4 6QG.

Professor Rebecca Jester

Adjunct Professor, Faculty of Health and Social Care, London South Bank University, London, SE1 0AA.

Professor Robert McKinley

Professor of Education in General Practice, Keele University Medical School, Staffordshire, ST5 5BG.

Dr. Alison Pooler

Lecturer, School of Nursing and Midwifery, Keele University, Staffordshire, ST4 6QG. 


\begin{abstract}
:
Background: Chronic venous leg ulcers are common, intractable and often recurrent but care is often wound focused, potentially overlooking the significant impact the condition has on the patients' daily life. A systematic review was undertaken to explore the factors that impact on the quality of life of the patient with chronic venous leg ulceration.
\end{abstract}

Methods: Eligible articles published between 1990 and 2013 were identified via electronic searches of research databases.

Results: Twenty-three studies (11 qualitative / 12 quantitative) met the inclusion criteria and were the subject of full review. The qualitative studies were collapsed into four core themes: physical, psychological, social implications and the nursepatient relationship. The quantitative studies were grouped according to the tool applied.

The review demonstrated that chronic venous leg ulcers impact negatively across all areas of daily living. Pain, exudate, odour and the impact on mobility were daily challenges. The ability to engage with everyday functioning was restricted either due to the ulcer, the dressing or due to a self-imposed isolation in response to the impact of symptoms. Depression and low mood were common and yet, despite this, some studies reported that participants remained hopeful.

Conclusion: Studies suggest that chronic venous leg ulceration negatively impacts on the quality of life of the patient and that such issues receive inadequate attention during current consultations. If such negative implications are to be effectively addressed, key issues need to be considered during every consultation.

Key words: venous leg ulceration; quality of life; wound care; chronic; systematic review.

Declaration of interest: This study was funded by West Midlands Strategic Health Authority. The authors have no conflicts of interest to declare. 


\section{Introduction.}

Chronic venous leg ulceration (CVLU) is a long term condition that affects many thousands of people worldwide, most often as a result of chronic venous insufficiency. ${ }^{1}$ The annual cost of the care and management of the condition is high and, with a global ageing population, is set to increase exponentially. ${ }^{1,2}$ The majority of care for these patients is delivered in the community, at a clinic location or at home, principally by teams of District Nurses (DN). ${ }^{3}$ Evidence demonstrates that high compression, multilayer bandaging represents the 'gold standard' approach to the management of CVLU which, when correctly applied, improves healing times when compared to the absence of compression. ${ }^{4,5}$ However, research suggests that much of the care for this patient group has an exclusive wound management focus which is of varying quality and little attention is paid to the impact that the ulceration poses on the individual. ${ }^{3}$ The personal cost to the patient and their carers, as a result of CVLU, is known to be significant and is often underestimated or overlooked by the healthcare professional (HCP). ${ }^{6}$

Research into the impact of CVLU to date demonstrates that quality of life (QoL) for the patient is limited;7,8 a factor that is potentially intensified by this 'wound care' focus to DN consultations. ${ }^{5,9}$ Previous reviews have demonstrated that CVLU impacts on the life both patients and carers, $3,10-13$ however these good quality reviews are now somewhat dated and, in the main, have focussed on a single methodology ${ }^{7}$ or patient group. ${ }^{10}$ The qualitative research provides a rich patient reflection on life with CVLU, providing insight into the feelings underpinning participant responses.7,11,13,14 The quantitative studies, in contrast, enumerate the impact using instruments to assess patient QoL.15,16 Evidence from both qualitative and quantitative studies, innovatively synthesised in this review, provides a more 'complete' picture of the impact of CVLU.

This review explores CVLU impact applying systematic methods, ${ }^{17-19}$ with sourced studies synthesised using a narrative approach and, where homogeneity has allowed, meta-analysis. ${ }^{20-21}$ The value of this review ${ }^{20}$ lies not only in the search and selection of the range of studies but also in the synthesis of extracted evidence leading to updated explanations and a strengthening of our understanding of the impact of CVLU. The question addressed by this review is: 


\section{Methods.}

A systematic search of multiple bibliographic databases (MEDLINE, CINAHL, BNI, EMBASE, PsycINFO, AMED and HMIC), Cochrane Collaboration database and Google Scholar was undertaken with each database searched individually, with search terms applied line by line and replicated in every source. Once complete, hand searching, reference and citation tracking was undertaken by two reviewers (JG \& RJ) who agreed the final selection of articles.

\section{Inclusion / exclusion criteria.}

The search period covered was 1990 - 2013 and included studies of adult patients located in primary care with CVLU and with a focus on QoL. Excluded studies were published prior to 1990, focused on a single domain of QoL such as pain, 22 were therapy, $^{23}$ product, $^{24,25}$ or intervention focused ${ }^{26,27}$ or developed, evaluated or compared QoL instruments without comparison data from unaffected subjects. ${ }^{28-30}$

\section{Search strategies.}

Comprehensive search terms, developed using the PECOs approach, ${ }^{31}$ were systematically applied along with Boolean operators. ${ }^{32}$ (Table 1) (Searches were undertaken July 2013).

Table 1: $\quad$ Search terms.

\begin{tabular}{|l|l|}
\hline $\mathbf{1}$ & venous ulcer* \\
\hline $\mathbf{2}$ & chronic venous insufficiency \\
\hline $\mathbf{3}$ & varicose ulcer* \\
\hline $\mathbf{4}$ & stasis ulcer* \\
\hline $\mathbf{5}$ & leg ulcer* \\
\hline $\mathbf{6}$ & chronic wound* \\
\hline $\mathbf{7}$ & MeSH leg ulcer \\
\hline $\mathbf{8}$ & OR all of the above \\
\hline $\mathbf{9}$ & quality of life \\
\hline $\mathbf{1 0}$ & "quality of life" \\
\hline $\mathbf{1 1}$ & health related quality of life \\
\hline $\mathbf{1 2}$ & "health related quality of life" \\
\hline $\mathbf{1 3}$ & MeSH quality of life \\
\hline $\mathbf{1 4}$ & OR 9 - 13 \\
\hline $\mathbf{1 5}$ & combine 9 AND 14 \\
\hline
\end{tabular}


Titles, abstracts and, finally, full text articles were screened against the inclusion criteria by two reviewers (JG \& RJ).

\section{Quality assessment.}

Appraisal of the quality of quantitative studies within systematic reviews is well established; indeed Moher et $\mathrm{al}^{33}$ identified the availability of 34 tools to facilitate such an appraisal in 199 - a total which is increasing and includes tools recommended by $\mathrm{CRD},{ }^{17} \mathrm{CASP}^{34}$ and a domain-based evaluation currently recommended by Cochrane. ${ }^{35}$ For the quality appraisal of qualitative studies there remains much debate, although this is an approach that is, on the whole, encouraged. ${ }^{35-40}$ Where a review involves 'disparate data' from differing research methods, ${ }^{36-38}$ quality appraisal is potentially even more complicated. In response to this, Hawker et $\mathrm{al}^{38}$ developed a framework to assess the quality of incongruent studies; whilst acknowledging that some would question whether qualitative and quantitative studies could be reviewed against the same criteria. The subsequent scoring system, ${ }^{38}$ based around a similar system used by the Critical Appraisal Skills Programme (CASP), ${ }^{34}$ sets out to provide an explicit indication of the strengths and weaknesses of the studies included in a review. Hawker et al's ${ }^{38}$ tool was selected to assess the quality of both the qualitative and quantitative studies included in this review as it is simple and provides an overall impression of study quality irrespective of method.

Hawker et al's ${ }^{38}$ system provides a summed score for nine aspects of study reporting including study methodology, each rated from 10 (very poor), 20 (poor), 30 (fair) and 40 (good). Scores are summed and evaluated in terms of Hawker et al (2002) guidelines: with scores of less than 90 deemed to indicate the study was of very poor quality; scores of 90-180 deemed to indicate poor quality; scores of 180-270 deemed of fair quality and 270-360 indicated good quality. ${ }^{38}$ The elements of reporting assessed for each publication are the abstract and title, introduction and aims, method and data, sampling, data analysis, ethics and bias, findings/results, transferability/generalisability and implications and usefulness. (Table 2). 


\section{Data extraction.}

Data was extracted and summarised using data extraction sheets for the qualitative and quantitative studies (Table 2). Standard data such as author and year of publication, location and duration, sample size, etc. were recorded along with the quality score (QS). ${ }^{38}$ The CASP ${ }^{34}$ approach to critical analysis was applied to ensure the quality, validity and relevance of the information extracted.

\section{Methods of Synthesis.}

The qualitative and quantitative studies were reviewed separately to ensure clarity. ${ }^{18}$ Synthesis of qualitative studies involved a process of thematic synthesis ${ }^{39}$ whereby the findings of multiple studies were coded, integrated and then grouped into themes. As a result, consistency of the review technique was maintained across the studies and themes that enhance our understanding of the QoL and CVLU were identified and thoroughly explored. ${ }^{18}$

The synthesis of the quantitative studies similarly involved a narrative thematic synthesis and, where homogeneity allowed, also includes a meta-analysis. ${ }^{39,40}$ For clarity, quantitative studies have been grouped according to the QoL instrument applied (eg. Short Form 36 (SF36), ${ }^{41}$ Nottingham Health Profile (NHP), ${ }^{42}$ etc), to enable themes to be compared and clearly reported. Review Manager 5.2 ${ }^{43}$ was used for the meta-analysis.

\section{Results.}

The search culminated in the selection of 24 articles reporting 23 studies selected for the final synthesis (Figure 1). Characteristics of the studies are summarised in Table 2 \& 3. 
Figure 1: Stages of article selection. ${ }^{17,33}$

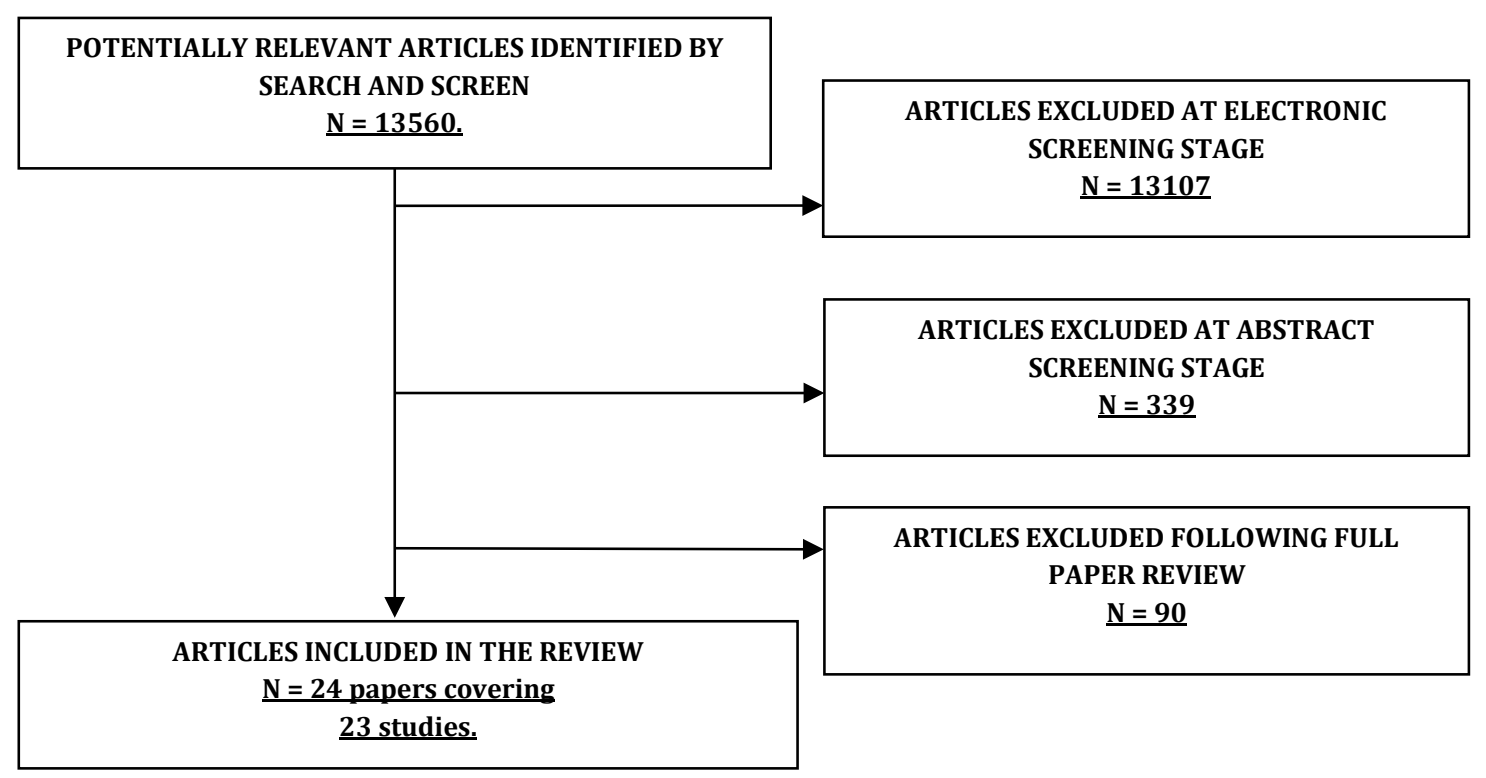


Table 2:

Qualitative studies (11 studies reported in 12 papers):

\begin{tabular}{|c|c|c|c|}
\hline Author, year \& location & Design of study & Participant characteristics & $\begin{array}{l}\text { Quality } \\
\text { score }\end{array}$ \\
\hline Bland (1996) NZ (45) & Heideggerian phenomenology; Single interview & n=9; Gender: 5 male; Age: 56-81 years; Aetiology not defined & QS: 130 \\
\hline Brown $(2005$ a \& b) UK $(44,52)$ & Phenomenology; Single interview & n=8; Gender not defined; Age: Over 65; All venous aetiology & QS: 290 \\
\hline Byrne \& Kelly (2010) ROI (51) & Heideggerian phenomenology; Single interview & $\mathrm{n}=12 ;$ Gender not defined; Age: Older people; All venous & QS: 160 \\
\hline Charles (1995) UK (46) & Phenomenology; Single interview & $\mathrm{n}=4 ;$ Gender: 3 male; Age: 43-62 years; All venous aetiology & QS: 170 \\
\hline Chase et al (1997) USA (13) & $\begin{array}{l}\text { Phenomenology; Single interview \& } 12 \text { month } \\
\text { review }\end{array}$ & n=7; Gender not defined; Age: no detail; All venous aetiology & QS: 240 \\
\hline Douglas (2001) UK (48) & Qualitative grounded theory; Single interview & $\mathrm{n}=8$; Gender: 2 male; Age: $65-94$ years; All venous aetiology & QS: 270 \\
\hline $\begin{array}{l}\text { Ebbeskog \& Ekman (2001) Sweden } \\
\text { (50) }\end{array}$ & Phenomenology; Single interview & $\mathrm{n}=15$; Gender: 3 men; Age: 74-89 years; All venous aetiology & QS: 320 \\
\hline Hopkins (2004) UK (49) & Hermeneutic phenomenology; Single interview & $\mathrm{n}=5$; Gender: 4 male; Age: 47-78 years; All venous aetiology & QS: 270 \\
\hline Hyde et al (1999) Aus (10) & Qualitative descriptive study; Single interview. & $\begin{array}{l}\mathrm{n}=12 ; \text { Gender: all female; Age range: } 70-93 \text { years; Aetiology not } \\
\text { defined }\end{array}$ & QS: 280 \\
\hline Rich \& McLachlan (2003) UK (11) & Phenomenology; Single interview & n=8; Gender: 3 male; Age: 55-89 years; All venous aetiology & QS: 340 \\
\hline Walshe (1995) UK (47) & Phenomenology; One occasion & n=13; Gender: 1 male; Age: elderly; All venous aetiology & QS: 330 \\
\hline
\end{tabular}

Quantitative studies (12 studies):

\begin{tabular}{|c|c|c|c|}
\hline Author, year \& country & Design of study & Participant characteristics & $\begin{array}{l}\text { Quality } \\
\text { score }\end{array}$ \\
\hline Charles (2004) UK (46) & Prospective quantitative review; 12 weeks & $\mathrm{n}=65$; Gender: 43\% male; Age: Median 72 years; Aetiology ND & QS: 230 \\
\hline Chase et al (2000) USA (55) & Quantitative descriptive study; SF-36 & $\mathrm{n}=21 ;$ Gender: 3 men; Age: $39-73$ years; All venous aetiology & QS: 230 \\
\hline Faria et al (2011) Brazil (56) & Quantitative study Single completion of SF36 & $\mathrm{n}=160$; Gender: $30 \%$ male; Age: $46-85$ years; All venous aetiology & QS:250 \\
\hline Franks \& Moffatt (1998) UK (14) & Cross sectional quantitative study; NHP & n=758; Gender: 272 male; Age: 74.6; Venous: $66 \%$ & QS: 310 \\
\hline Franks \& Moffatt (2001) UK (15) & Quantitative study; 12 week study NHP & N=383; Gender: 37\% male; Age: median 74 years. & QS: 330 \\
\hline $\begin{array}{l}\text { Franks, McCullagh \& Moffatt (2003) } \\
\text { UK (57) }\end{array}$ & Prospective quantitative; SF36 start \& 12 weeks. & $\mathrm{n}=118$; Gender: $27 \%$ male; Age: mean 78 years; Aetiology ND & QS: 310 \\
\hline Franks et al (2006) UK (59) & Cross sectional quantitative; NHP over 48 weeks & $\begin{array}{l}\mathrm{n}=95 \text {; Gender: } 35 \text { male; Age: median age } 76 \text { years; multiple } \\
\text { aetiologies. }\end{array}$ & QS: 350 \\
\hline Furtado et al (2008) Portugal (60) & Cross sectional quantitative study: NHP, EQ \& VAS & $\begin{array}{l}98 \text { at baseline / } 68 \text { FU at } 12 \text { weeks; Age: Mean age 71.9; } \\
\text { Aetiology: ND }\end{array}$ & QS: 320 \\
\hline Heinan et al (2006) NL (62) & Descriptive, cross-sectional quantitative study & $\mathrm{n}=141 ;$ Gender: $37 \%$ male; Age: $29-92$ years; Venous $50 \%$ & QS: 340 \\
\hline Jull et al (2004) NZ (16) & Case control comparing SF-36 scores to AEN & $\mathrm{n}=465$; Gender: 41\% male; Age: mean age 75 years; Aetiology ND & QS: 330 \\
\hline Lindholm et al (1993) Sweden (58) & Postal survey NHP on one occasion & $\mathrm{n}=125$; Gender: 51 male; Age: range $36-93$ years; All aetiologies & QS: 240 \\
\hline Wissing et al (2002) Sweden (61) & Quantitative study: PGCMAI on one occasion & $\mathrm{n}=144 ;$ Gender: 44 male; Age: mean 79 years; aetiology ND & QS: 230 \\
\hline
\end{tabular}


Table 3: Characteristics of studies.

\begin{tabular}{|l|l|l|l|l|l|l|l|}
\hline Design & Date & $\begin{array}{l}\text { Number } \\
\text { of } \\
\text { studies }\end{array}$ & Participants & Gender & $\begin{array}{l}\text { Age } \\
\text { range }\end{array}$ & Sample size & Quality score \\
\hline Qualitative & $\begin{array}{l}1995- \\
2010\end{array}$ & 11 & 106 & $\begin{array}{l}68 \% \\
\text { female }\end{array}$ & $43-94$ yrs & $\begin{array}{l}4-15 \\
\text { (Mdn: 8) }\end{array}$ & $\begin{array}{l}3 \text { poor, } 1 \text { fair \& } \\
7 \text { good. }\end{array}$ \\
\hline Quantitative & $\begin{array}{l}1993- \\
2012\end{array}$ & 13 & 2545 & $\begin{array}{l}57 \% \\
\text { female }\end{array}$ & $25-92$ yrs & $\begin{array}{l}21-758 \\
\text { (Mdn: } 141)\end{array}$ & 5 fair \& good. \\
\hline
\end{tabular}

\section{Qualitative studies.}

The eleven qualitative studies selected for the review contained 41 subthemes which, using a process of narrative thematic synthesis, $32,39,40$ have been integrated to four overarching theme. ${ }^{17}$

1) The physical implications of CVLU;

2) The psychological implications of CVLU;

3) The social implications of CVLU;

4) The nurse-patient relationship.

Each of the themes comprised a number of related subthemes. These are displayed in Figure 2. 
Figure 2: Thematic map of qualitative themes.

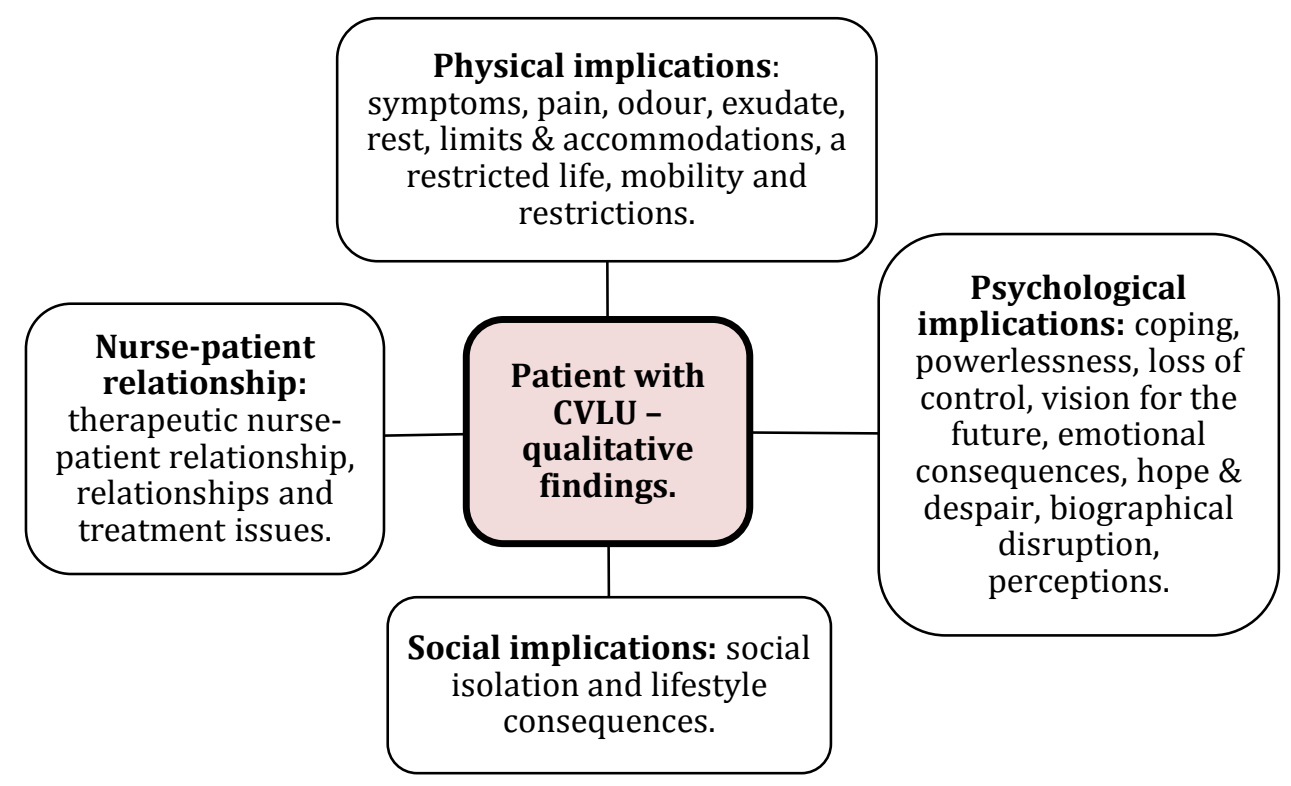

\section{Physical Implications.}

\section{Pain:}

Pain was a dominant theme and was consistent across all studies. It was significant, described as the worst symptom and the cause of enormous suffering. ${ }^{7,44,45}$ Pain was overwhelming, incessant and unrelenting; it had profound effects on the patient, impacting on their sleep, mobility and day-to-day functioning and was exacerbated by both dressings and treatment regimens. ${ }^{10,47-48}$ Pain, for some, was a 'constant companion', it persistently reminded them of the unremitting nature of their ulceration, ${ }^{47-49}$ controlling their existence and making them angry, sad and 'to cry in despair'.50,p.239

The control of pain was also problematic; $45,47,48,51$ respondents often under-reported pain $^{47,48}$ and were reluctant to take analgesia which was deemed ineffective. Participants reported that pain management was an area of care that was often poorly managed. 11 


\section{Exudate and Odour:}

Eight of the eleven studies referred to issues due to leakage from the wound and the associated malodour 10,11,45,47-51 Exudate was unbearable and devastating, ${ }^{11}$ with the unpredictability of dressing leakage causing distress and shame. ${ }^{51}$ There were reports of wet shoes, wet bedding and concerns of what people might think. ${ }^{48}$ Where leakage was associated with malodour, the impact was even greater and the symptoms were often inadequately managed. ${ }^{45,47}$ These symptoms were of particular concern and had an even greater impact when the patient was working. ${ }^{11}$ Participants felt that mechanisms to manage exudate and odour were consistently inadequate, with the odour being described as the worst thing associated with ulceration. 45,47,48 The leakage and odour resulted in limitations to social contacts, self-consciousness and a feeling that matters that should remain private had somehow become public with efforts to improve symptoms most often proving to be inadequate. ${ }^{13,47}$

\section{Mobility and daily living.}

Six studies referred to mobility issues. ${ }^{13,44,47,48,50,51}$ Mobility was restricted by ulcer pain, wound leakage or the 'restrictions' of the dressings applied.10,13,47,48,50 Many were housebound due to their CVLU; ${ }^{47}$ unable to work or to socialise. These issues were exacerbated by the fear of sustaining further injuries. ${ }^{44}$ Participants reflected on these limitations with a sense of loss and resignation. ${ }^{51}$

\section{Sleep.}

Sleep disturbances featured in six studies reviewed $11,46-48,50,51$ and were most often attributed to ulcer-related pain, which negatively impacted on well-being. Participants reported that it was rare to experience a full night of sleep, which resulted in daytime tiredness and a lack of strength and energy. ${ }^{50}$ Their subsequent fatigue further reduced their well-being. ${ }^{11,50}$

\section{Other subthemes.}

Studies revealed a number of other areas of physical functioning that were restricted due to ulceration. There were difficulties in maintaining personal hygiene, raised in five of the studies, which further impacted on perceptions of well-being and contributed to 
social isolation. $11,45,47,48,50$ Respondents also reported not having their feet washed for long periods, ${ }^{13,45,47,50}$ which resulted in worries about odour and further exacerbated their social isolation.

Five of the studies explored issues relating to sourcing adequate, comfortable footwear and suitable clothing which would effectively conceal the dressings.10,11,13,49,50 Hyde et $\mathrm{al}^{10}$ in their study of female participants, found respondents had to modify clothing to conceal their ulceration and referred to the limitations of choices of clothing as yet another restriction to their personal style and a further erosion of their femininity.

\section{Social Implications.}

All eleven studies referred to the impact of CVLU on social life due to wound leakage and malodour, with some participants reporting that they excluded themselves from society to avoid embarrassment. ${ }^{10,40,49,50}$ Some participants reflected on a desire to avoid subjecting those close to them to the effects of the exudate and voluntarily excluding themselves from engaging in social activity due to their fear of how people might react to them. ${ }^{49,50} \mathrm{~A}$ feeling that private things had been moved into the public domain was the response of participants ${ }^{49}$

Hyde et $\mathrm{al}^{10}$ reported a self-inflicted social isolation as an attempt to limit further damage to legs and to prevent ulcer recurrence. Patients spoke of looking forward to an end of ulceration so that they could initiate social interaction again; their time with ulcers was referred to as 'wasted days'.13,47,50 Brown ${ }^{44}$ referred to this social disconnectedness as being separate from everyday society, almost an introverted and closed life of social isolation. ${ }^{11,56}$

For some participants their ulcers limited ability to work; ${ }^{49,50}$ one participant retired due to his ulcer, a situation he had resigned himself to but felt that his ulcer had cost him both his freedom and his livelihood..$^{10,51}$

\section{Psychological Implications.}

These were reflected in all studies. Hopkins ${ }^{49}$ described a concept of 'biographical disruption' where a clear distinction was made between life before and after ulceration. Participants expressed feelings of loss but, despite this, many spoke of hope for the 
future. ${ }^{45,49,50}$ The disparity between hope and expectations appeared important in terms of coping. ${ }^{11,50}$ Hyde et $\mathrm{al}^{10}$ reported an inner strength; a determination, resilience and hope for a future once healed. Some participants were preoccupied with their ulcer ${ }^{47}$ whereas others, in contrast, coped by normalising the effect of ulceration. ${ }^{49}$ Some struggled with feelings of self-disgust and were pessimistic about healing; ${ }^{47}$ which they termed a 'forever healing'. ${ }^{13}$ For some role reversal had occurred with family members; those previously at the head of the family were now dependent on others for help and support. $^{48}$

\section{Nurse-patient relationship.}

Nine studies described the importance of the nurse-patient relationship,11,13, 44-50 with reflections that this was one of the only positive aspects of CVLU. Nurses reportedly went beyond the necessity of their visits and enjoyed a 'laugh and a joke'.13,47,49 Some studies reported inconsistencies in and dissatisfaction with the care provided by nurses, especially temporary or agency nurses - the continuity of the nurse was paramount; some even complained of the time wasted whilst they waited for nurse visits. ${ }^{13,44,46,51,52}$ In spite of this, on the whole, participants remained grateful and trusted in their nursing staff.10,11,48 Studies did reveal, however, an overall lack of understanding of the underlying causes and treatment of ulceration, which served to exacerbate feelings of powerlessness and may result in some compliance issues. ${ }^{13,48}$ In spite of these factors, patients were grateful for the care provided, especially for the personal characteristics of the nurses. ${ }^{10,11}$

\section{Results of quantitative studies.}

The quantitative studies applied a range of established QoL instruments. The Short Form 36 (SF-36) (5), ${ }^{45}$ the Nottingham Health Profile (NHP) (5) ${ }^{42}$ and the remaining a combination of other instruments. Meta-analysis was undertaken where possible, otherwise synthesis is purely narrative.

\section{Studies using the SF-36}

The SF-36 is a self-completed, generic health survey that provides QoL information. ${ }^{41}$ It has been widely evaluated and has proven validity and reliability. ${ }^{3}$ Completion 
provides scores across eight domains (physical function, role-physical, bodily pain, general health, vitality, social functioning, role-emotional, mental health), with lower scores indicating limited functioning in that area. Five studies published between 1995 and 2011 used the SF-36 to evaluate the QoL of 829 participants with CVLU. ${ }^{16,54-57}$ Two ${ }^{16,57}$ used a control group, the remaining three used Age Equivalent Norms (AEN) from which to bring comparisons. In some of the more recent studies composite scores were calculated to indicate overall physical and mental component scoring (PCS and MCS), however since these were not available for four of the selected studies they have not been utilised. Two of the studies ${ }^{54,57}$ recoded SF-36 scores at entry to the study and after 12 weeks in order to observe for improvements over time and with healing. The remaining three studies applied the SF-36 on a single occasion.

Despite this variation of comparator scores, CVLU participants demonstrated consistently poor QoL across all 8 domains. Physical functioning was reduced in all five studies and even persisted after healing. ${ }^{54,57}$ The role-physical domain was also diminished across the studies. Participants in four studies reported increased bodily pain, ${ }^{16,55-57}$ although pain improved over time irrespective of healing. General health was least and inconsistently compromised. Vitality was also reduced in all studies. Social functioning was reduced across four studies. ${ }^{16,55-57}$ Role-emotional scores were consistently reduced. Mental health was impaired in four studies, however, the participants in Chase et al's ${ }^{54}$ study were less compromised than others.

Three studies involving a total of 779 participants were sufficiently homogenous for meta-analysis. ${ }^{16,54,57}$ (Figure 3) A meta-analysis refers to a statistical 'pooling' of data to allow for scores from a number of studies to be compared and contrasted in order to ascertain similarities or differences. ${ }^{18}$ In order for a meta-analysis to be undertaken, the studies need to be homogenous in terms of population, exposure, comparator and outcome (PECOs). ${ }^{31}$ For the quantitative studies reviewed here, only three demonstrated sufficient similarity in the reporting of data to be included in a metaanalysis. ${ }^{16,54,57}$ 
Figure 3: Forest plot for SF36.

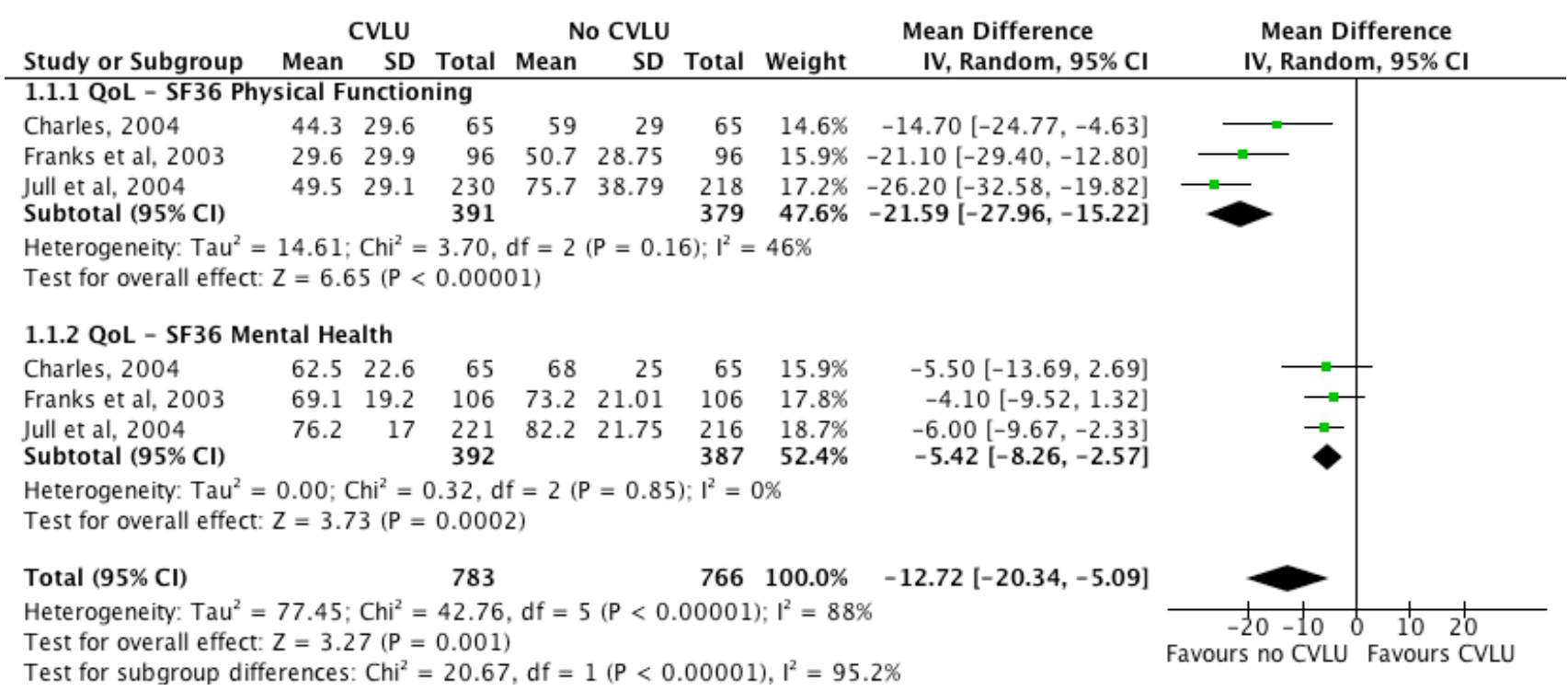

The pooled mean difference between study participants and the study comparator for QoL physical functioning was -21.59 (95\% CI: -27.96 to $-15.22 ; \mathrm{p}<0.00001)$ and QoL mental health was -5.42 (95\% CI: -8.26 to $-2.57 ; \mathrm{p}$ 0.0002). This meta-analysis demonstrates a consistently lower mean score, and thus diminished QoL, for patients with CVLU when compared to those without ulceration on review of SF36 completion ${ }^{41}$ across these three studies. ${ }^{16,54,57}$ Such meta-analysis strengthens individual study results.

\section{Studies using the NHP.}

The NHP is a self-completed, generic QoL survey that provides QoL information. ${ }^{42}$ Again it is widely evaluated with proven validity and reliability. ${ }^{34}$ Completion relates to the subjective assessment of physical, emotional and social aspects of health for the respondent, with higher scores over six domains (energy, bodily pain, emotion, sleep, social isolation, mobility) reflecting poorer levels of health. Five studies between 1995 and 2008 used the NHP to determine QoL of 1459 participants. ${ }^{14,15,58-60}$ Two $^{14,60}$ utilised AENs for comparison; 32 two reported serial NHP scores ${ }^{15,59}$ and one was reported narratively, ${ }^{58}$ without scoring detail. This lack of consistency of reporting demonstrates considerable heterogeneity and precluded a meta-analysis; studies are therefore reported narratively. 
Lindholm et $a^{58}$ concluded that CVLU had a marked impact on subjectively assessed health. Analysis of NHP scores, recorded on a single occasion, was compared with age / gender adjusted norms with distinctions made on occupational / class status. Men with CVLU had higher scores in the energy domain when compared with both female respondents with CVLU and the general population. High pain scores were reported in both male and female participants. Female respondents had similar emotion scores as the general population but men's were higher. Sleep scores were slightly higher for women but consistently higher for men. Social isolation scores were the same as the general population for female respondents but males demonstrated elevated scores. In the area of mobility, female respondents had slightly elevated scores whereas their male counterparts were significantly higher.

Franks and Moffatt ${ }^{14,15}$ and Franks et al $^{59}$ conducted a number of studies to explore QoL of patients with CVLU using the NHP. Only in the 1998 study, ${ }^{14}$ with data collected on a single occasion, were comparisons made with the general population by gender. Two studies $^{15,59}$ were conducted over an extended period of 12 weeks and 48 weeks respectively. Three studies ${ }^{14,15,59}$ demonstrated reduced QoL across all six domains at baseline; with greatest impairment in mobility, pain and energy. Franks and Moffatt's ${ }^{14}$ and Franks et al's ${ }^{59}$ studies showed improvements in scores over 12 and 24 weeks respectively but were not sustained at 48 weeks. These authors ${ }^{14,15,59}$ concluded that CVLU impacts on all areas of QoL albeit with differences by age and gender.

Furtado et al ${ }^{60}$ compared the NHP to the Portuguese AEN. Only bodily pain was statistically significantly reduced yet there were significant improvements over the 12 weeks of the study. Where ulcer healing had occurred, improvements were seen in social isolation, sleep and energy compared to non-healed counterparts.

Overall, all of the studies ${ }^{14,15,58-60}$ that applied the NHP reported reduced functioning across the six domains, demonstrating compromised QoL for those with CVLU. Studies conclude that these limitations were attributable to CVLU and, significantly, Franks et $\mathrm{al}^{59}$ demonstrated that improvements recorded in the short term (12 week) were not sustained at 48 weeks. 


\section{Studies using other instruments.}

The remaining two studies used a number of other generic instruments. ${ }^{61,62}$ Wissing et al ${ }^{61}$ undertook a case control study in Sweden which compared 70 patients with leg ulceration with 74 elderly patients without leg ulceration, although recruitment was not randomised. The questionnaire used was the Philadelphia Geriatric Center Multilevel Assessment Instrument (PGCMAI)62 which assesses well-being and behavioural competence with low scores indicating compromised functioning. Participants with CVLU demonstrated lower scores through all domains when compared to the control group. This revealed compromised functioning in physical health, activities of daily living, cognition, time management, social interaction, psychological well-being and environmental quality. ${ }^{61}$

Heinen et $\mathrm{al}^{62}$ undertook their study across seven hospitals in the Netherlands $(\mathrm{n}=141)$ with data collected using interviews, questionnaires and wound assessment. Sampling was not randomised but included all with an open ulcer and who spoke Dutch. The questionnaires applied included the Sickness Impact Profile, ${ }^{64}$ Cantril's ladder of life, ${ }^{65}$ the Barthel index ${ }^{65}$ and the subjective sleep quality scale. ${ }^{66}$ These were accompanied with interviews and wound observations. Results demonstrated a negative effect of ulcer related problems with pain, mobility and difficulties getting adequate footwear impacting significantly on QoL. Problems with sleep, wound care, daily activities and negative emotions were present as a result of CVLU.62

\section{Discussion.}

Studies demonstrate that CVLU is a debilitating condition, characterised by long periods of ulceration, and where healing is achieved, a high incidence of recurrence exists. ${ }^{1-3}$ Significant, QoL limiting symptoms are the common theme across the research presented and the negative impact that the ulceration has on the psychological wellbeing of the sufferer is also an important feature; with feelings of low self-esteem, frustration and inadequacy being frequently reported. ${ }^{45-48}$ Self-imposed social isolation either to protect from further damage or to limit the exposure of others to the debilitating symptoms of ulceration was widespread and served to reduce the QoL of the participants. ${ }^{11}$ 
The qualitative studies reported the impact of CVLU on all aspects of daily living with pain dominating the lives of many ${ }^{12,55,56}$ and limited sleep a further problem.52,56 Exudate and odour caused embarrassment, resulting in social isolation, low mood, depression and poor self-esteem. ${ }^{10,11,55,56}$ The ability of participants to maintain adequate standards of personal hygiene was restricted $10,55,56$ and choices of clothes and shoes limited, ${ }^{49,50}$ which further limited self-esteem. ${ }^{50}$

The quantitative studies similarly reported poor QoL, with limitations across every area of functioning, whether physical, social or psychological. Scores were lower when compared to the AEN and improvements, due to healing, were not sustained over longer durations. ${ }^{59}$ All of the data presented supports the notion that CVLU is a long term condition, with sustained healing unlikely which results in pervasive and long term limitation to patient functioning.

This review is innovative in its synthesis of quantitative and qualitative evidence and inclusion of a meta-synthesis of the impact of CVLU on QoL. It extends the previous work of Persoon et $\mathrm{al}^{3}$ and Herber et al. ${ }^{12}$ The strengths include the robust search strategy, study selection, paired review and the application of an innovative 'disparate evidence' quality scoring tool. ${ }^{38}$ This is the first meta-analysis of the impact of CVLU on the lives of patients and has clearly quantified it's impact. 16,54,57 Studies that constructed, validated or evaluated QoL instruments were excluded which has served to enhance the patient focus of the review. ${ }^{3,12}$ The review was time limited and had limited funding.

\section{Implications for practice and research.}

This review has stark implications for practice. Firstly, current clinical practice focuses care on the wound and healing, 5,9 which participants report is insufficient. Despite the known value of multilayer high compression, care is often inconsistent and of varying quality.3-5 Pain, exudate and malodour are major causes of distress which reduce QoL and need to be more effectively addressed. ${ }^{44-49}$ And finally, the relationship between the patient and their nurse, including the importance of continuity of care, needs to be recognised.13,44,46,51,52 While some of the issues can be alleviated by good clinical practice (for example, gold standard ulcer management, 4,5 inquiring about pain and advising patients to take analgesia before dressings are changed) others will require 
further research (for example, whether increasing relationship continuity ${ }^{67}$ between patient and nurse improves QoL and healing times).

\section{Conclusion.}

This review explored studies that evaluated the impact of CVLU on patient QoL. It demonstrates the extensive impact of CVLU across all areas of participant functioning. The consistently negative implications of CVLU that the reviewed studies report span a 16 year period and clearly demonstrate a need for innovative research into potential solutions to these issues. 


\section{References:}

1. Posnett, J. \& Franks,P. (2007). The costs of skin breakdown and ulceration in the UK. In Smith and Nephew Foundation Skin Breakdown - The silent epidemic. UK: snfoundation.

2. Persoon, A., Heinen, M., van der Vleuten, C., de Rooij, M., van de Kerkhof, P. \& van Achterberg, T. Leg Ulcers: a review of their impact on daily life. Journal of Clinical Nursing. 2004; 13, 341354.

3. Nelzen, O., Bergqvist, D. \& Lindhagen, A. (1997). Long term prognosis for patients with chronic leg ulcers: a prospective study. European Journal of Vascular and Endovascular Surgery. $13,500-508$.

4. SIGN (2010). 120: Management of chronic venous leg ulcers. A national clinical guideline. Accessed at: http://sign.ac.uk/guidelines/fulltext/120/recommendations.html on 17/11/14 2250 hrs.

5. BMJ Clinical Evidence (2011). Leg Ulcers: Venous. Accessed at: http://cks.nice.org.uk/legulcer-venous\#!topicsummary on 17/11/14 2245hrs.

6. Franks, P. \& Moffatt, C.J. Leg Ulcers in Smith and Nephew Foundation (2007) Skin Breakdown

- The silent epidemic. 2007; UK: snfoundation.

7. Briggs, M. \& Flemming, K. Living with leg ulceration: a synthesis of qualitative research. Journal of Advanced Nursing. 2007; 59 (4), 319-328.

8. Krasner, D. Painful venous ulcers: themes and stories about their impact on quality of life. Ostomy Wound Manage 1998,44(9):38-46.

9. Callam, M., Ruckley, C., Harper, D. \& Dale, J. Chronic ulceration of the leg: extent of the problem and provision of care. British Medical Journal. 1985; 290,1855-1856.

10. Hyde, C., Ward, B., Horsfall, J. \& Winder, G. Older women's experience of living with chronic leg ulceration. International Journal of Nursing Practice. 1999; 5,189-198.

11. Rich, A. \& McLachlan, L. How living with a leg ulcer affects people's daily life: a nurse-led study. Journal of Wound Care. 2003; 12 (2), 51-54.

12. Herber, O. R., Schnepp, W. \& Rieger, M. A. A systematic review on the impact of leg ulceration on patients. Health and Quality of Life Outcomes. 2007; 5, 44-56.

13. Chase, S., Melloni, M. \& Savage, A. A forever healing: The lived experience of venous ulcer disease. Journal of Vascular Nursing. 1997; XV, 73-78.

14. Franks, P. \& Moffatt, C. Who suffers most from leg ulceration? Journal of Wound Care. 1998; 7 (8), 383-385.

15. Franks, P. \& Moffatt, C.J. Health related quality of life in patients with venous ulceration: Use of the Nottingham health profile. Quality of Life Research. 2001; 10, 693-700. 
16. Jull, A., Walker, N., Hackett, M., Jones, M., Rodgers, A., Birchall, N., Norton, R. \& MacMahon, S. Leg ulceration and perceived health: a population based case-study control. Age and Ageing. 2004; 33, 236-241.

17. Centre for Reviews and Dissemination. Systematic Reviews. CRD's guidance for undertaking reviews in health care. 2009; CRD: York.

18. Booth, A., Papaioannou, D. \& Sutton, A. Systematic approaches to a successful literature review. 2012; Thousand Oaks, CA: Sage.

19. Popay, J., Roberts, H., Sowden, A., Petticrew, M., Britten, N., Arai, L., Roen, K. \& Rodgers, M. Developing guidance on the conduct of narrative synthesis in systematic reviews. Journal of Epidemiology Community Health. 2005; 59 Suppl 1, A7.

20. Lucas, P. J., Baird, J., Aria, L., Law, C. \& Roberts, H. M. Worked examples of alternative methods for the synthesis of qualitative and quantitative research in systematic reviews. BMC Medical Research Methodology. 2007; 7(4), 2-13.

21. Rodgers, M., Sowden, A., Petticrew, M., Arai, L., Roberts, H., Britten, N. \& Popay, J. Testing methodological guidance on the conduct of narrative synthesis in systematic reviews. Evaluation. 2009; 15 (1), 49-74.

22. Guarnera, G., Tinelli, G., Abeni, D., Di Pietro, C., Sampogna, F. \& Tabolli, S. Pain and quality of life in patients with vascular leg ulcers: an Italian multicentre study. Journal of Wound Care. 2007; 16 (8), 347-351.

23. Watson, J., Kang'ombe, A., Soares, M., Chuang, L., Worthy, G., Bland, M., Iglesias, C., Cullum, N., Torgerson, D. \& Nelson, E, A. Use of weekly, low dose, high frequency ultrasound for hard to heal venous leg ulcers: the VenUS II controlled trial. BMJ. 2011. Acessed: http://www.ncbi.nlm.nih.gov/pmc/articles/PMC3050437/pdf/bmj.d1092.pdf

at $23.25 \mathrm{hrs}$ on $25 / 07 / 2013$.

24. Bjellerup, M., Lindholm, C., Christensen, 0. \& Zederfeldt, B. Analysis of therapy-resistant venous leg ulcers. Wound Repair and Regeneration. April-June, 54-62.

25. Kirby, J. (2008). Case study: caring for a patient with a highly exuding leg ulcer. Journal of Community Nursing. 1993; 19 (6), 28-32.

26. Collins, K., Morrell, J., Peters, J. \& Walters, S. Variations in venous leg ulcer care in the community. British Journal of Community Nursing. 1998; 3, 6-12.

27. Edwards, H., Courtney, M., Finlayson, K., Lewis, C., Lindsay, E. \& Dumble, J. Improved healing rates for chronic venous leg ulcers: Pilot study results from a randomised controlled trial of a community nursing intervention. International Journal of Nursing Practice. 2005; 11, 169-176.

28. Hareendran, A., Bradbury, A., Budd, J., Geroulakos, G., Hobbs, R., Kenkre, J. \& Symonds, T. Measuring the impact of venous leg ulcers on quality of life. Journal of Wound Care. 2005; 14 (2), 53- 57. 
29. Walters, S., Morrell, C.J. \& Dixon, S. Measuring health-related quality of life in patients with venous ulceration. Quality of Life Research. 1999; 8, 327-336.

30. Iglesias, C. P., Birks, Y., Nelson, E. A., Scanlon, E. \& Cullum, N. A. Quality of life of people with venous leg ulcers: A comparison of the discriminative and responsive characteristics of two generic and a disease specific instruments. Quality of Life Research. 2005; 14, 1705-1718.

31. National Collaborating Centre for Methods and Tools (2012). Defining your question: PICO and $P S$ Hamilton, ON: McMaster University. Retrieved: http://www.nccmt.ca/registry/view/eng/138.html accessed at $08.40 \mathrm{am}$ on 22/07/2013.

32. Hicks, C. (2004). Research Methods for Clinical Therapists.London: Churchill Livingstone, 1

33. Moher, D., Liberati, A., Tetzlaff, J.\& Altman, D. G. The PRISMA Group. (2009). Preferred Reporting Items for Systematic Reviews and Meta-Analyses. The PRISMA Statement. PLoS Med 6(6): e1000097. doi:10.1371/journal.pmed1000097

34. Critical appraisal skills programme (2010). Critical appraisal skills programme: making sense of the evidence about clinical effectiveness: 11 questions to help you make sense of a trial. Accessed at:

http://www.casp-uk.net/wp-

content/uploads/2011/11/CASP RCT Appraisal Checklist 14oct10.pdf at 08.30hrs on $22 / 07 / 2013$.

35. Higgins, J. P. T. \& Green, S. (ed) (2011). Cochrane Handbook for Systematic Reviews of Interventions Version 5.1.0. The Cochrane Collaboration, 2011. Available from www.cochranehandbook.org.

36. Goldsmith, M. R., Bankhead, C. R. \& Austoker, J. (2007). Synthesising quantitative and qualitative research in evidence- based patient information. J Epidemiol Community Health. 61, 262-270.

37. Mays, N., Pope, C. \& Popay, J. (2005). Systematically reviewing qualitative and quantitative evidence to inform management and policy-making in the health field. J Health Serv Res Policy. 10:S6-20.

38. Hawker, S., Payne, S., Kerr, C., Hardey, M. \& Powell, J. Appraising the evidence: reviewing disparate data systematically. Qualitative Health Research. 2002; 12 (9), 1284-1299.

39. Thomas, J., Harden, A., Oakley, A., Oliver, S., Sutcliffe, K., rees, R., Brunton, G. and Kavanagh, J. (2004). Integrating qualitative research with trials in systematic reviews. BMJ. 328, 7446, 10102.

40. Briggs, M. (2009) Synthesizing data from qualitative research. European Wound Management Association Journal. 9 (2), pp. 24-25.

41. Ware, J. \& Sherbourne, C. The MOS 36-item Short-Form health survey (SF-36): 1. Conceptual Framework and item selection. Medical Care. 1992; 30, 473-483.

42. Hunt, S., McEwen, J. \& McKenna, S. Measuring health status. London: Croom Helm, 1985. 
43. Review Manager (RevMan) [Computer program]. (2012). Version 5.2. Copenhagen: The Nordic Cochrane Centre, The Cochrane Collaboration.

44. Brown, A. Chronic leg ulcers, part 2: do they affect a patient's social life? British Journal of Nursing. 2005b; 14 (18), 986-989.

45. Bland, M. Coping with leg ulcers. Kai Taki Nursing New Zealand. April, 13-14, 1996.

46. Charles, H. Does leg ulcer treatment improve patients' quality of life? Journal of Wound Care. 2004; 13 (6), 209-213.

47. Walshe, C. Living with a venous leg ulcer: a descriptive study of patients' experiences. Journal of Advanced Nursing. 1995; 22, 1092-1100.

48. Douglas, V. Living with a chronic leg ulcer: an insight into patients' experiences and feelings. Journal of Wound Care. 2001; 10 (9), 355-360.

49. Hopkins, A. Disrupted lives: investigating coping strategies for non-healing leg ulcers. British Journal of Nursing. 2004; 13 (9), 556-563.

50. Ebbeskog, B \& Ekman, S. Elderly people's experiences: the meaning of living with venous leg ulcer. European Wound Management Association Journal. 2001; 1 (1), 21-23.

51. Byrne, O. \& Kelly, M. (2010). Living with a chronic leg ulcer. Journal of Community Nursing. 2010; 24(5), 46-54.

52. Brown, A. Chronic leg ulcers, part 1: do they affect a patient's social life? British Journal of Nursing. 2005a; 14 (17), 894-898.

53. Cox, D.R., Fitzpatrick, R., Fletcher, A.E., Gore, S.M., Spiegelhalter, D.J. \& Jones, D.R. Quality-ofLife Assessment: Can We Keep It Simple? Journal of the Royal Statistical Society. 1992; 155 (3), 353-393

54. Charles, H. (2004). Does leg ulcer treatment improve patients' quality of life? Journal of Wound Care. 13 (6), 209-213.

55. Chase, S., Whittemore, R., Crosby, N., Freney, D., Howes, P. \& Phillips, T. Living with chronic venous leg ulcers: a descriptive study of knowledge and functional status. Journal of Community Health Nursing. 2000; 17 (1), 1-13.

56. Faria, E., Blanes, L., Hochman, B., Filho, M. \& Ferreirra, L. Health-related quality of life, selfesteem, and functional status of patients with leg ulcers. Wounds. 2011; 23 (1), 4-10.

57. Franks, P., McCullagh, L. \& Moffatt, C. J. Assessing quality of life with chronic venous leg ulceration using the Medical Outcomes Short Form-36 questionnaire. Ostomy Wound Management. 2003; 49, 26-37.

58. Lindholm, C., Bjellerup, M., Christensen, 0. \& Zederfeldt, B. Quality of Life in Chronic Leg Ulcer Patients. Acta Derm Venereol. 1993; 73, 440-443.

59. Franks, P., Moffatt, C.J., Doherty, D.C., Smithdale, R. \& Martin, R. Longer-term changes in quality of life in chronic leg ulceration. Wound Repair and Regeneration. 2006; 14, 536 - 541. 
60. Furtado, K., Pina, E. Moffatt, C.J. \& Franks, P, J. Leg ulceration in Portugal: quality of life. International Wound Journal. 2008; 5 (1), 34-39.

61. Wissing, U., Ek, A., Wengstrom, Y., Skold, G. \& Unosson, M. Can individualised nutritional support improve healing in therapy-resistant leg ulcers? Journal of Wound Care. 2002; 11(1), 15-20.

62. Heinen, M. M., Persoon, A., van de Kerkhof, P., Ptero, M. \& Achterberg, T. Ulcer-related problems and health care needs in patients with venous leg ulceration: A descriptive, crosssectional study. International Journal of Nursing Studies. 2007; 44, 1296-1303.

63. Lawton, M.P., Moss, M., Fulcomer, M. \& Kleban, M.H. A research and service oriented Multilevel Assessment Instrument. Journal of Gerontology. 1982; 37, 91-99.

64. de Bruin, A. F., Diederiks, J. P., de Witte, L. P., Stevens, F. C. \& Philipsen, H. Assessing the responsiveness of a functional status measure: the Sickness Impact Profile versus the SIP68. Journal of Clinical Epidemiology. 1997; 50 (5): 529-540

65. Cantril, H. The pattern of human concerns. New Brunswick: Rutgers University Press, 1965.

66. Mahoney, F. I. \& Barthell, D. W. Functional Evaluation: the Barthell Index. Maryland State Medical Journal. 1965; 14, 61-65.

67. Freeman, G. \& Hughes, J. Continuity of care and the patient experience. London, King's Fund, 2010. 